\title{
Editorial: Microbial food and feed ingredients - reconciling tradition and novelty
}

\author{
Hansen, Egon Bech; Nielsen, Dennis Sandris; LaPointe, Gisèle
}

Published in:

FEMS Microbiology Letters

Link to article, DOI:

10.1093/femsle/fnz130

Publication date:

2019

Document Version

Publisher's PDF, also known as Version of record

Link back to DTU Orbit

Citation (APA):

Hansen, E. B., Nielsen, D. S., \& LaPointe, G. (2019). Editorial: Microbial food and feed ingredients - reconciling tradition and novelty. FEMS Microbiology Letters, 366(11), [fnz130]. https://doi.org/10.1093/femsle/fnz130

\section{General rights}

Copyright and moral rights for the publications made accessible in the public portal are retained by the authors and/or other copyright owners and it is a condition of accessing publications that users recognise and abide by the legal requirements associated with these rights.

- Users may download and print one copy of any publication from the public portal for the purpose of private study or research.

- You may not further distribute the material or use it for any profit-making activity or commercial gain

- You may freely distribute the URL identifying the publication in the public portal

If you believe that this document breaches copyright please contact us providing details, and we will remove access to the work immediately and investigate your claim 


\section{Editorial: Microbial food and feed ingredients - reconciling tradition and novelty}

Microbial food and feed ingredients is the topic for this thematic issue of FEMS Microbiology Letters. We have for the purpose loosely defined microbial food and feed ingredients as ingredients composed of microorganisms or produced by fermentation. We recognize that this group of ingredients does not constitute a well-defined category neither legally nor commercially. In spite of the fuzziness in the definition, we believe that microbial ingredients possess special advantages and special challenges regarding innovation potential, consumer acceptance and regulatory approval.

The First Microbial Food and Feed Ingredients (MIFFI) Conference (https://miffi.org) held in Copenhagen May 2-4, 2018 focused on these aspects and most of the papers in the present thematic issue originate from presentations given at the MIFFI2018 conference.

Legally, food ingredients are defined as everything used to prepare the food product; however, the term 'food ingredient' is commonly used to designate the ingredients that contribute to functionalities in excess of expectations based on amounts used. The functionalities provided by food and feed ingredients cover a diverse field including but not limited to preservation against spoilage (aerobic and microbial), emulsification, texturizing, flavor, sweetness, nutrition and health. The chemistry of food and feed ingredients is also quite diverse ranging from extracts of natural sources to synthetic molecules not normally occurring in nature. In addition, the regulatory framework around food and feed ingredients show considerable diversity across the globe. In regulatory language, such ingredients are typically defined as additives or processing aids depending on the presence in the final product.

Consumers have an ambiguous attitude towards food additives as they might want the functionality provided by the ingredient whereas the consumption of 'unnatural' or chemical products is generally perceived as undesirable. Although the definition of unnatural or chemical is quite challenging, this consumer attitude might generally be advantageous for microbial food and feed ingredients.

The MIFFI Conference created a forum for scientists working on multiple aspects of microbial food and feed ingredients. The participants exchanging views, ideas, and results came from academia, industrial research, development, application and regulatory departments, government agencies, consumer analysts etc.

The papers in this thematic issue of FEMS Microbiology Letters capture highlights of some of the creative exchanges at
MIFFI2018 in the form of minireviews, research letters and a current opinion.

The minireviews cover the fields of legal aspects, bioengineering and applications. Two minireviews, (Bourdichon, Laulund and Tenning 2019; Herman et al. 2019) address aspects of the safety evaluation of microorganisms used in food, pointing out problematic issues and recommendations for the future. Two minireviews (Chen et al. 2018; Börner et al. 2019) present the current methods for strain improvements using microfluidics and genome editing respectively. In the field of applications, Wiese (2019) review the effect of pectin as an animal prebiotic, highlighting the contribution of in vitro tools to complement in vivo studies. There remain many challenges to resolving the relationship between structure and functionality of prebiotics in order to develop applications for both animals and humans, but this review provide a solid foundation for this work. Marcial-Coba, Knøchel and Nielsen (2019) review low moisture foods as carriers for probiotics, pointing out their advantages in long shelf life and reducing costs. The use of lactic acid bacteria in food, feed and particularly in green refineries is reviewed by Lübeck and Lübeck (2019). Sustainable technologies are the wave of the future, and these authors show how fermentation with lactic acid bacteria can add value to feed, leading to detoxification and improved milk production.

Original research on microbial food and feed ingredients in this thematic issue is presented in research letters spanning a wide range of topics pertinent to the applications of lactic acid bacteria and probiotics. High-throughput screening revealed the rare strains suitable as texturing agents (Poulsen, Derkx and Oregaard 2019). Genome analysis contributed to the selection of starters as processing aids for cheese in order to avoid strains producing biogenic amines (Markusková et al. 2018). Comparetive genome analysis was used by Andersen, Pedersen and BangBerthelsen (2019) to investigate the role of mobile genetic elements in strain evolution and adaption of metabolic capabilities. Bacteriophages are receiving renewed interest these years, both for e.g. clinical purposes, but also for plant protection where Carstens et al. (2019) demonstrate the potential of a 6 strain phage cocktail to reduce Pectobacterium atrosepticum soft rot infection in potato tubers possibly reducing postharvest losses. The role of probiotics and synbiotics as tools to improve health in production animals is addressed by Skjøt-Rasmussen et al. (2019) describing in ovo administration of probiotics to obtain colonization of the young chicken from the time of hatching and by śliżewska et al. (2019) reporting on the effect of synbiotics on broiler chicken. The crucial role of the gut microbiome 
in human health and disease has become evident over the latest decade and Akkermansia muciniphila has emerged as a potential next-generation probiotic. However, oxygen sensitivity and limited stability at room or even refrigeration temperature of this bacterium makes logistics difficult when conducting e.g. clinical trials. Marcial-Coba et al. (2019) elegantly demonstrate that chocolate can be used as an efficient carrier of A. muciniphila even offering protection against the stress encountered during passage of the upper gastro-intestinal tract. The complex microbial community of a traditional Ethiopian fermented dairy product Dhanaan was analyzed by metagenomics methods in order to assess safety and to identify candidates of lactic acid bacteria as potential starter cultures for camel dairy products (Berhe et al. 2019).

The current opinion paper by Hartmann, Behrendt and Frøst (2019) presents the view that fermentation can be a driver for innovation in gastronomy. This commentary is establishing a bridge between microbiology and the pleasures of life and the paper captures that microorganisms can provide novel functionalities and remain rooted in tradition.

Plenty of aspects of Microbial Food and Feed Ingredients have not been covered in this thematic issue. We hope that those large white areas on the map can inspire novel contributions at the next MIFFI conference in 2020.

We look forward to seeing you at MIFFI2020.

\section{Conflicts of interests. None declared.}

\section{REFERENCES}

Andersen J, Pedersen CM, Bang-Berthelsen CH. Omics based comparative analysis of Mobile Genetic Elements in Lactococcus lactis. FEMS Microbiol Lett 2019;366.DOI: 10.1093/femsle/fnz102.

Berhe T, Ipsen R, Seifu E et al. Metagenomic analysis of bacterial community composition in dhanaan: Ethiopian traditional fermented camel milk. FEMS Microbiol Ecol 2019.DOI: 10.1093/femsle/fnz128.

Börner RA, Kandasamy V, Axelsen AM et al. Genome editing of lactic acid bacteria: Opportunities for food, feed, pharma and biotech. FEMS Microbiol Lett 2019;366:1-12.

Bourdichon F, Laulund S, Tenning P. Inventory of microbial species with a rationale: a comparison of FIL-IDF / EFFCA inventory of microbial food cultures and EFSA biohazard qualified presumption of safety. FEMS Microbiol Lett 2019;366.DOI: 10.1093/femsle/fnz048.

Carstens AB, Djurhuus AM, Kot W et al. A novel six-phage cocktail reduces Pectobacterium atrosepticum soft rot infection in potato tubers under simulated storage conditions. FEMS Microbiol Lett 2019;366. DOI: 10.1093/femsle/fnz101.
Chen J, Vestergaard M, Shen J et al. Droplet-based microfluidics as a future tool for strain improvement in lactic acid bacteria. FEMS Microbiol Lett 2018;365:1-7.

Hartmann AL, Behrendt RA, Frøst MB. Fermentation as a driver for food innovation. FEMS Microbiol Lett 2019;366.DOI: 10.1093/femsle/fnz058.

Herman L, Chemaly M, Cocconcelli PS et al. The qualified presumption of safety assessment and its role in EFSA risk evaluations: 15 years past. FEMS Microbiol Lett 2019;366:1-7.

Lübeck M, Lübeck PS. Application of lactic acid bacteria in green biorefineries. FEMS Microbiol Lett 2019;366:1-8.

Marcial-Coba MS, Knøchel S, Nielsen DS. Low-moisture food matrices as probiotic carriers. FEMS Microbiol Lett 2019;366:111.

Marcial-Coba MS, Saaby L, Knøchel S et al. Dark chocolate as a stable carrier of microencapsulated Akkermansia muciniphila and Lactobacillus casei. FEMS Microbiol Lett 2019;366:1-6.

Markusková B, Lichvariková A, Szemes T et al. Genome analysis of lactic acid bacterial strains selected as potential starters for traditional Slovakian bryndza cheese. FEMS Microbiol Lett 2018;365:1-7.

Poulsen VK, Derkx P, Oregaard G. High-throughput screening for texturing Lactococcus strains. FEMS Microbiol Lett 2019;366:17.

Skjøt-Rasmussen L, Sandvang D, Blanch A et al. Post hatch recovery of a probiotic Enterococcus faecium strain in the yolk sac and intestinal tract of broiler chickens after in ovo injection. FEMS Microbiol Lett 2019;366.DOI: 10.1093/femsle/fnz078.

Śliżewska K, Markowiak P, Żbikowski A et al. Effects of synbiotics on the gut microbiota, blood and rearing parameters of broiler chickens. FEMS Microbiol Lett 2019.DOI: 10.1093/femsle/fnz116.

Wiese M. The potential of pectin to impact pig nutrition and health: feeding the animal and its microbiome. FEMS Microbiol Lett 2019;366:1-15.

Egon Bech Hansen

National Food Institute, Technical University of Denmark, Kemitorvet, Building 202, 2800 Kgs. Lyngby, Denmark

Dennis Sandris Nielsen University of Copenhagen, Department of Food Science, Rolighedsuej 26, 1958 Frederiksberg C, Denmark

Gisèle LaPointe Canadian Research Institute for Food Safety, Department of Food Science, University of Guelph, 43 McGiluray St, Guelph, ON N1G 2W1, Canada 